\title{
Neurotrophin Signaling through the p75 Receptor Is Deficient in traf6-/- Mice
}

\author{
E. Carden Yeiser, ${ }^{1}$ Nancy J. Rutkoski, ${ }^{1}$ Asuka Naito, ${ }^{2}$ Jun-ichiro Inoue, ${ }^{2}$ and Bruce D. Carter ${ }^{1}$ \\ ${ }^{1}$ Department of Biochemistry and Center for Molecular Neuroscience, Vanderbilt University Medical School, Nashville, Tennessee 37232, and ${ }^{2}$ Division of \\ Cellular and Molecular Biology, Department of Cancer Biology, Institute of Medical Science, University of Tokyo, Tokyo 108-8639, Japan
}

Activation of the neurotrophin receptor $\mathrm{p} 75$ has been shown to elicit opposing cellular signals. Depending on the context of the cell, p75 will either promote survival or induce apoptosis after neurotrophin stimulation. p75-induced apoptosis occurs through activation of c-Jun N-terminal kinase (JNK), whereas the survival signal is mediated by nuclear factor $\kappa \mathrm{B}(\mathrm{NF} \kappa \mathrm{B})$. The receptor proximal signals that produce these responses are unknown, although several molecules have been identified that associate with the intracellular domain of p75. One such interactor, TRAF6, a member of the tumor necrosis factor receptor-associated factor family, has been implicated in p75 signaling. To assess the role of TRAF6 in p 75 signaling, we analyzed mice with this gene deleted. In Schwann cells isolated from traf6 $+/+$ animals, NGF elicited an $80 \%$ increase in transcription of an NF $\kappa$ B reporter; however, in traf6-/- cells, the NGF response was abrogated. Similarly, NGF activation of JNK was not apparent in Schwann cells from mice lacking traf6. Deficiencies in p75 signaling in traf6-/animals resulted in a loss of p75-mediated apoptosis. In sympathetic neurons cultured from traf6+/+ superior cervical ganglia (SCGs), there was an increase in JNK activation and apoptosis after BDNF binding to p75; however, traf6-/- neurons did not respond. In vivo during naturally occurring cell death, there was a 55.6\% reduction in TUNEL (terminal deoxynucleotidyl transferase-mediated biotinylated UTP nick end labeling)-positive cells in the SCG of postnatal day 4 traf6-/- animals relative to traf6+/+ littermates. These results indicate that TRAF6 plays an essential role in mediating p75 signal transduction and induction of apoptosis.

Key words: NGF; BDNF; TNF; neuron; apoptosis; NF $\kappa \mathrm{B}$

\section{Introduction}

The p75 neurotrophin receptor is a multifunctional protein with numerous ligands and downstream functions. The receptor binds all neurotrophins, including nerve growth factor (NGF), brain-derived neurotrophic factor (BDNF), neurotrophin-3, and neurotrophin-4, with similar affinity (Huang and Reichardt, 2001). In addition, p75 interacts with the Nogo receptor, which binds to inhibitors of neurite outgrowth expressed by oligodendrocytes (Wang et al., 2002; Wong et al., 2002). p75 also interacts with members of the Trk family of tyrosine kinase receptors to form a high-affinity neurotrophin receptor complex that promotes survival and differentiation of specific neurons during vertebrate development (Barbacid, 1994). Activation of the p75 receptor can elicit a variety of responses, including induction of apoptosis, promotion of cell survival, peripheral nerve myelination, and regulation of neurite extension, depending on the cellular context.

Received Nov. 25, 2003; revised 0ct. 6, 2004; accepted 0ct. 14, 2004.

This work was supported by National Institutes of Health (NIH)-National Institute of Neurological Disorders and Stroke Grant NS38220 (B.D.C.) and National Institute of Diabetes and Digestive and Kidney Diseases Training Grant DK07061-29 (E.C.Y.). Experiments were performed in part through the use of the Vanderbilt University Medical Center Research Electron Microscopy Resource (sponsored by NIH Grants DK20539 and DK58404). We are grateful to Dr. Moses Chao for the 75 antisera and to members of the Carter laboratory for valuable suggestions.

Correspondence should be addressed to Dr. Bruce D. Carter, Department of Biochemistry, Center for Molecular Neuroscience, 655 Light Hall, Vanderbilt University Medical School, Nashville, TN 37232. E-mail: bruce. carter@vanderbilt.edu.

DOI:10.1523/JNEUROSCI.1390-04.2004

Copyright $\odot 2004$ Society for Neuroscience ～0270-6474/04/2410521-09\$15.00/0
Neurotrophin binding to 75 has been shown to stimulate cell death in a large number of cultured cells (for review, see Roux and Barker, 2002). In vivo the receptor has been implicated in the naturally occurring cell death of developing retinal cells (Frade et al., 1996; Frade and Barde, 1998), spinal motorneurons (Frade and Barde, 1999), cholinergic neurons of the basal forebrain (Frade and Barde, 1999), trigeminal neurons (Davey and Davies, 1998), and sympathetic neurons of the superior cervical ganglia (SCGs) (Bamji et al., 1998; Majdan et al., 2001). In contrast to its apoptotic effects, p75 can also promote cell survival, e.g., in sensory neurons deprived of trophic support (Longo et al., 1997), hippocampal neurons treated with glutamate (Bui et al., 2002), and subplate neurons during development of the rodent cortex (DeFreitas et al., 2001; McQuillen et al., 2002). How these dichotomous signals are generated and what determines the ultimate cellular outcome has yet to be fully elucidated; however, p75 activation of the transcription factor nuclear factor $\kappa \mathrm{B}(\mathrm{NF} \kappa \mathrm{B})$ has been implicated in the pro-survival response (Hamanoue et al., 1999; Foehr et al., 2000; Gentry et al., 2000), whereas stimulation of the stress kinase, c-Jun N-terminal kinase (JNK), is required for the pro-death signal (Casaccia-Bonnefil et al., 1996; Yoon et al., 1998; Harrington et al., 2002).

Much of the effort to understand how this receptor activates $\mathrm{NF} \kappa \mathrm{B}$ and JNK has focused on identifying proteins that interact with the intracellular domain (ICD). One such receptor binding protein, TRAF6, a member of the tumor necrosis factor (TNF) receptor-associated factor (TRAF) family, associates with p75 in a 
ligand-dependent manner (Khursigara et al., 1999). TRAF6 has been shown to interact with several receptors including CD40 (Ishida et al., 1996), interleukin-1 (IL-1) receptor (Cao et al., 1996), receptor activator of $\mathrm{NF} \kappa \mathrm{B}$ (RANK), and toll-like receptors (TLRs) (Lomaga et al., 1999), and in mice lacking the traf6 gene, activation of $\mathrm{NF} \kappa \mathrm{B}$ and $\mathrm{JNK}$ by these receptors is defective, leading to deficiencies in bone formation and B-cell maturation (Lomaga et al., 1999; Naito et al., 1999).

In the context of p75 signaling, TRAF6 has been suggested to mediate p75 signaling to $\mathrm{NF} \kappa \mathrm{B}$ based on results from use of a dominant-negative TRAF6 construct (Khursigara et al., 1999; Foehr et al., 2000). However, ectopic expression of TRAF6 and p75 in fibroblasts was not able to reconstitute NGF activation of $\mathrm{NF} \kappa \mathrm{B}$, whereas expression of another signaling protein, receptorinteracting protein-2 (RIP2), with the receptor was sufficient (Khursigara et al., 2001). Therefore, we sought to address the role of TRAF6 in p75 signal transduction through analysis of traf6 $-/-$ mice. Our results demonstrate that TRAF6 is required for p75-mediated activation of $\mathrm{NF} \kappa \mathrm{B}$ and JNK; moreover, this signal mediator is necessary for the receptor-mediated apoptosis in sympathetic neurons.

\section{Materials and Methods}

Breeding and genotyping of traf6-deficient mice. The generation of mice with a deletion in the TRAF6 gene has been described previously (Naito et al., 1999; Yoshida et al., 2002). All experiments were performed in Black 6 or 129SV strains of mice with no observed difference between strains. The genotyping was performed by PCR analysis as described by Naito et al. (1999).

Schwann cell cultures. Sciatic nerves from postnatal day 2 (P2) to $\mathrm{P} 4$ traf $6+/+$, traf $6+/-$, and traf $6-/-$ pups were isolated, and the Schwann cells were dissociated by trituration after digestion with $0.25 \%$ trypsin and $0.3 \%$ collagenase for $30 \mathrm{~min}$ at $37^{\circ} \mathrm{C}$. The Schwann cells were cultured on poly-D-lysine (Sigma, St. Louis, MO)-coated 48-well (for NF $\kappa \mathrm{B}$ assays) or 6-well (for Western) plates in DMEM (Invitrogen, Gaithersburg, MD) containing $10 \%$ fetal calf serum, $100 \mathrm{U} / \mathrm{ml}$ penicillin, 100 $\mu \mathrm{g} / \mathrm{ml}$ streptomycin, and glial growth factor (GGF; $50 \mathrm{ng} / \mathrm{ml}$; R \& D Systems, Minneapolis, MN). The Schwann cells were maintained in the presence of GGF for $1-2 \mathrm{~d}$ before evaluation of NF $\kappa \mathrm{B}$ activation and $12 \mathrm{~d}$ before evaluation of JNK activation.

$N F \kappa B$ reporter assay. Activation of $\mathrm{NF} \kappa \mathrm{B}$ was assessed in primary cultures of Schwann cells, 1 or $2 \mathrm{~d}$ after isolation, using a luciferase reporter, $6 \mathrm{X} \kappa \mathrm{B}-\mathrm{Luc}$ (a gift from Larry Kerr). The cells were transfected with $0.1 \mu \mathrm{g}$ of $6 \mathrm{X} \kappa \mathrm{B}-\mathrm{Luc}$ reporter and $0.01 \mu \mathrm{g}$ of RSV-Renilla (used as internal control for transfection efficiency) per well of a 48-well plate using Effectene (Qiagen, Hilden, Germany) according to the manufacturer's protocol. After $24 \mathrm{hr}$, the cells were washed once in serum-free DMEM and treated with $100 \mathrm{ng} / \mathrm{ml} \mathrm{NGF}$ or $25 \mathrm{ng} / \mathrm{ml}$ TNF (R \& D Systems) for 4-6 hr and lysed in $100 \mu \mathrm{l}$ of reporter lysis buffer (Promega, Madison, WI). Luciferase activity was measured according to the manufacturer's (Promega) instructions using a luminometer (Monolight 2010; Analytical Luminescence Laboratory). The results were normalized to the basal activity for each treatment and genotype. There was no consistent difference in the basal activity between genotypes, although there was considerable variability.

Western blotting. Schwann cells were maintained in culture for $12 \mathrm{~d}$ and then washed twice with serum-free, GGF-free DMEM, then treated in DMEM with NGF $(100 \mathrm{ng} / \mathrm{ml})$, TNF $(25 \mathrm{ng} / \mathrm{ml})$, or left untreated for $5 \mathrm{hr}$ at $37^{\circ} \mathrm{C}$. The cells were then lysed on ice in Tris lysis buffer $(20 \mathrm{~mm}$ Tris, $\mathrm{pH}$ 7.5, $137 \mathrm{~mm} \mathrm{NaCl}, 2$ mм EDTA, pH 7.4, 1\% Triton X-100, 25 mм $\beta$-glycerophosphate, 2 mм Na-pyrophosphate, $1 \mathrm{~mm}$ Na vanadate, $1 \mathrm{~mm}$ PMSF, and $10 \mu \mathrm{g} / \mathrm{ml}$ aprotinin), and equal amounts of protein were separated on a $10 \%$ SDS-polyacrylamide gel and transferred to a nitrocellulose membrane (Protran). Immunoblot analysis was performed using rabbit anti-phospho-JNK (1:1000; Cell Signaling Technology) and rabbit anti-pan-JNK (1:1000; Santa Cruz Biotechnology, Santa Cruz, CA).

For Western analysis of the expression of various signaling proteins in
TRAF6-deficient brains, brains were removed from P3 or P4 pups after decapitation and sonicated in radioimmunoprecipitation assay lysis buffer (50 mu Tris- $\mathrm{HCl}, \mathrm{pH}$ 8.0, $150 \mathrm{~mm} \mathrm{NaCl}, 1 \% \mathrm{NP}-40,0.5 \%$ deoxycholate, $0.1 \%$ SDS, $0.5 \mathrm{~mm}$ PMSF, $2 \mu \mathrm{g} / \mathrm{ml}$ leupeptin, and $2 \mu \mathrm{g} / \mathrm{ml}$ aprotinin). Proteins were then separated by SDS-PAGE, transferred to nitrocellulose, and then the blot was probed with an antibody against the extracellular domain of p75 (1:1000; generously provided by M. V. Chao, Skirball Institute, New York University, New York, NY), anti-TrkA (1: 1000; Santa Cruz Biotechnology), anti-RIP2 (also referred to as RICK; 1:1000; Stressgen), anti-phospho-c-Jun (specific for the phosphorylation sites on Ser 63; 1:500; Cell Signaling Technology), anti-c-Jun (1:1000; Cell Signaling Technology ), rabbit anti-phospho-JNK (1:1000; Cell Signaling Technology ), anti-pan-JNK (1:1000; Santa Cruz Biotechnology), and anti- $\alpha$ tubulin ( $3 \mu \mathrm{g} / \mathrm{ml}$; Oncogene).

Neuronal cultures. SCGs were isolated from traf $6+/+$, traf $6+/-$, and traf6-/- pups on P3-P4. The sympathetic neurons were isolated and cultured based on methods described previously (Palmada et al., 2002). In brief, after dissociation with $0.25 \%$ trypsin (Worthington, Freehold, $\mathrm{NJ}$ ) and $0.3 \%$ collagenase (Sigma), the neurons were cultured on polyL-ornithine- and laminin-coated plastic 4-well slides (Nalge Nunc, Naperville, IL) at a density of 4000-5000 cells/well in UltraCULTURE media (BioWhittaker, Walkersville, MD) containing 3\% fetal calf serum, $100 \mathrm{U} / \mathrm{ml}$ penicillin, $100 \mu \mathrm{g} / \mathrm{ml}$ streptomycin, $1 \mu \mathrm{g} / \mathrm{ml}$ gentamicin, $10 \mu \mathrm{M}$ fluorodeoxyuridine (Sigma), and $20 \mathrm{ng} / \mathrm{ml} \mathrm{NGF} \mathrm{(Harlan} \mathrm{Labs,} \mathrm{Indianap-}$ olis, IN). The neurons were maintained for $3-5 \mathrm{~d}$ in the presence of NGF before being used for survival assays or immunostaining after NGF withdrawal or p75 activation.

Sympathetic neuron survival assays. For NGF withdrawal experiments, NGF was removed by washing the SCG neurons three times in UltraCULTURE media lacking NGF and treated with antibody to NGF at 0.1 $\mu \mathrm{g} / \mathrm{ml}$ (Chemicon, Temecula, CA). For the p75 activation experiments, NGF was removed in the same manner, and the cells were then cultured with $12.5 \mathrm{~mm} \mathrm{KCl}$ to allow for survival in the absence of NGF. p75 activation was achieved by treating cells with $200 \mathrm{ng} / \mathrm{ml} \mathrm{BDNF}$ (a gift from Regeneron, Tarrytown, NY). After the $48 \mathrm{hr}$ treatment period in NGF-free or BDNF-containing media, cells were fixed in $4 \%$ paraformaldehyde and mounted using Vectashield with 4',6-diamidino-2phenylindole (DAPI; Vector Laboratories, Burlingame, CA) to visualize the nucleus. Viable neurons, based on nonapoptotic nuclei and neurite extensions at least twice the length of the soma, were counted in nine random fields (at least 50 neurons counted per well). Control values for each genotype are set at 100\% survival, and the data for the experimental conditions are presented as percentage of survival compared with control. Control conditions were either neurons maintained in NGF for the NGF withdrawal experiments or neurons maintained in $12.5 \mathrm{~mm} \mathrm{KCl}$ for the BDNF experiments. Statistical results were expressed as the mean \pm SEM and were tested for significance using Student's $t$ test and ANOVA.

For assessing the role of JNK activation in p75-mediated cell death, recombinant adenoviruses were used, one expressing dominant-negative green fluorescent protein (GFP)-tagged JNK2 and the other expressing GFP, as a control (kindly provided by S. O. Yoon, Ohio State University, Columbus, $\mathrm{OH}$ ) (Harrington et al., 2002). The neurons were cultured for $3 \mathrm{~d}$ in $20 \mathrm{ng} / \mathrm{ml} \mathrm{NGF}$, infected with $1.6 \times 10^{6}$ particles $/ \mathrm{ml}$ of recombinant adenovirus for $2 \mathrm{hr}$ in serum-free media, then serum-containing, NGFpositive media were re-added. One day after infection, the virus was removed and cells were fed with fresh media. The next day, NGF-free media containing $12.5 \mathrm{~mm} \mathrm{KCl}$ with or without $200 \mathrm{ng} / \mathrm{ml} \mathrm{BDNF}$ (as described above) was added to the cultures. Survival assays under conditions of p75 activation were performed by counting all neurons (viable and apoptotic) in nine random fields. The percentage of survival for each condition was determined by dividing the total cell number by the number of live cells.

Immunostaining. Neurons grown as described above were rinsed in PBS, fixed in $4 \%$ paraformaldehyde, permeabilized for $2-20 \mathrm{~min}$ at $4{ }^{\circ} \mathrm{C}$ in PBS plus $0.1 \%$ Triton X-100 (PT), and blocked with 5\% goat serum in PT, followed by avidin-biotin block (Vectastain; Vector Laboratories). To visualize c-Jun and phospho-c-Jun, cells were incubated with anti-cJun or anti-phospho-c-Jun (1:500; Cell Signaling Technology) for $1 \mathrm{hr}$ at room temperature, followed by biotinylated anti-rabbit and Cy3- 
conjugated strepavidin or anti-rabbit AlexaFluor 488 (Molecular Probes, Eugene, OR). Phospho-JNK immunostaining was performed as above using a polyclonal anti-phospho-JNK antibody (1:1000; Biosource, Camarillo, CA). Slides were mounted using Vectashield with DAPI.

The neurons were cultured either in the presence or absence of NGF for $24 \mathrm{hr}$, or in the presence of $12.5 \mathrm{~mm} \mathrm{KCl}$ with or without BDNF for 15-24 hr. After the treatments, viable neurons, based on nonapoptotic nuclei and neurite extensions at least twice the length of the soma, were counted in nine random fields. For each viable neuron (between 50 and 250 cells were counted per experimental condition), c-Jun-positive nuclei were counted, and the data are expressed as the percentage of c-Junpositive nuclei. Control values for each genotype were set at $100 \%$, and the data for the experimental conditions are presented as percentage of immunopositive nuclei relative to control. TNF treatment, known to activate JNK in a p75- and TRAF6-independent manner, was also performed as a positive control for c-Jun accumulation in the nucleus. Cells maintained in the presence of NGF for several days were treated with 25 $\mathrm{ng} / \mathrm{ml} \mathrm{TNF}$ for $24 \mathrm{hr}$, fixed, and immunostained as described previously. Phospho-c-Jun counts were performed in the same manner as that for c-Jun counts. For the phospho-JNK evaluation, cells were treated with BDNF or TNF for $8-24 \mathrm{hr}$, fixed, immunostained, and mounted with DAPI. Viable cells were counted. For each viable cell, the number of those cells expressing phospho-JNK was determined, and the data are expressed as the percentage of phospho-JNK-positive cells relative to control.

In vivo SCG terminal deoxynucleotidyl transferase-mediated biotinylated UTP nick end labeling staining. On P4 and P12, both SCGs were removed from traf $6+/+$, traf $6+/-$, and traf $6-/-$ mice and snap-frozen on dry ice. Whole frozen SCGs were serially cut on a cryostat, and every third section was mounted onto Superfrost-charged microscope slides (Fisher Scientific, Pittsburgh, PA). SCGs sections were dried overnight at room temperature and then rehydrated through a graded series of ethanols the following day. After fixation in $4 \%$ paraformaldehyde, the sections were terminal deoxynucleotidyl transferase-mediated biotinylated UTP nick end labeling (TUNEL) stained (in situ cell detection kit; Boehringer Mannheim, Indianapolis, IN) as described by the manufacturer's instructions. This particular TUNEL kit uses an FITC-labeled UTP, therefore we also mounted the slides with DAPI to morphologically verify condensed apoptotic nuclei also positive for TUNEL. Using conventional epifluorescence, TUNEL-positive cells that also had condensed DAPI nuclei were directly counted. At least four sections per animal were counted. Statistical results from ANOVA were expressed as the mean number of TUNEL-positive cells per section for each genotype \pm SEM with $n=9$ for traf $6+/+$ and traf $6+/-$ mice and $n=7$ for traf6-/- mice at P4.

Morphometric analysis of traf6+/+ and traf6-/-SCGs. For morphometric analysis of the SCGs from wild-type and null littermates, after weighing the pups, the SCGs were removed from each animal at P7-P8, before death of the null animals that usually die at approximately P12. Tissue for quantitative evaluation was fixed in $4 \%$ paraformaldehyde in PBS for $1 \mathrm{hr}$ at room temperature, followed by an overnight incubation in $4 \%$ paraformaldehdye at $4^{\circ} \mathrm{C}$. Tissue was washed in $0.1 \mathrm{M}$ Sorenson's phosphate buffer, dehydrated through a graded series of ethanol to $100 \%$ ethanol, and embedded in Spurr resin. Thick $(5 \mu \mathrm{m})$ sections were cut at $50 \mu \mathrm{m}$ intervals through the entire ganglia. The total area of ganglia represented in each cross section was estimated using standard point counting (Weibel, 1989), and the total number of neurons with nucleoli was counted for every cross section. For each ganglion, 15 sections were counted, and the total neuronal number per total section area was compared between wildtype and null littermates using a paired Student's $t$ test.

\section{Results}

TRAF6 is required p75 activation of NF $\kappa B$ and JNK in Schwann cells

Because TRAF6 was previously implicated in p75 signaling in Schwann cells, we first evaluated receptor function in these cells, derived from mice lacking the traf6 gene. Schwann cells were isolated from traf $6+/+$, traf $6+/-$, and traf $6-/-$ mice, trans-

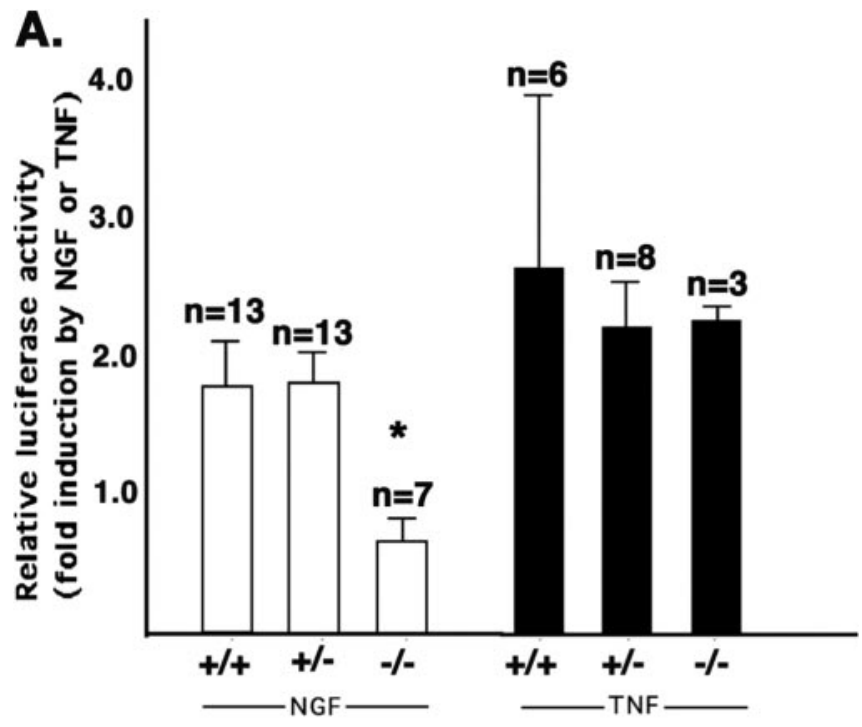

B.

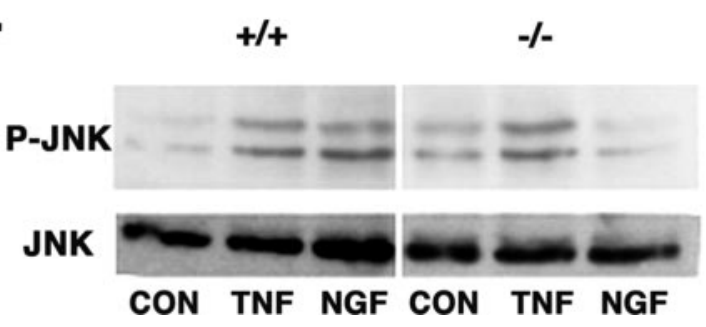

Figure 1. TRAF6 is required for $p 75$-mediated activation of NF $\kappa$ B and JNK in Schwann cells. $A$, Schwann cells isolated from traf6 $+/+$, traf6 $+/-$, and traf6 $-/-$ P2-P4 mouse pups were transfected with an NF $\kappa$ B luciferase reporter within $48 \mathrm{hr}$. One day after transfection, cells were treated in serum-free media with $100 \mathrm{ng} / \mathrm{ml} \mathrm{NGF}, 25 \mathrm{ng} / \mathrm{ml} \mathrm{TNF}$, or left untreated for $4-6$ $\mathrm{hr}$, then lysates were collected and luciferase activity was measured. All values were normalized to control cells (in serum-free media alone). Shown are the means \pm SEM for the indicated number of experiments. ${ }^{*} p<0.05$; statistical significance based on an ANOVA analysis. $B$, Schwann cells isolated from P2-P5 traf6 $+/+$ and traf6 $-/-$ mouse pups were cultured in serum and GGF for $12 \mathrm{~d}$; the GGF was then washed out, and the cells were treated in DMEM with $100 \mathrm{ng} / \mathrm{ml}$ NGF or left untreated for $5 \mathrm{hr}$. Whole-cell lysates were then separated by SDS-PAGE and subjected to Western blot analysis for phospho-JNK and total JNK after NGF or TNF treatment. The Western blot shown is representative of three experiments.

fected with a NF $\kappa \mathrm{B}$ luciferase reporter, and then treated with NGF for 4-6 hr. We assessed the activation of NF $\kappa \mathrm{B}$ within $2 \mathrm{~d}$ of isolating the cells, because Khursigara et al. (1999) found that after several days in vitro Schwann cells no longer induce $\mathrm{NF} \kappa \mathrm{B}$ activity in response to NGF treatment because of RIP2 downregulation. Under serum-free conditions, to optimize the activation of NF $\kappa$ B (Bhakar et al. 1999), NGF treatment of wild-type and heterozygous traf6 Schwann cells led to an approximate twofold increase in luciferase activity, whereas no increase above basal activity was ever observed in cells lacking TRAF6 after NGF treatment (Fig. 1A). This result indicates that TRAF6 is an essential player in the pathway from $\mathrm{p} 75$ to activated $\mathrm{NF} \kappa \mathrm{B}$, in agreement with the previous findings (Khursigara et al., 1999; Foehr et al., 2000).

Although the focus on TRAF6 in relation to p75 has been on its ability to activate $\mathrm{NF} \kappa \mathrm{B}$, for several other cytokine receptors this signal transducer has also been shown to be an essential upstream component of the JNK pathway (Lomaga et al., 1999; Kobayashi et al., 2001). Because neurotrophin binding to p75 has been shown to activate JNK, we considered the possibility that TRAF6 may also function in transducing this signal. To evaluate 
A.

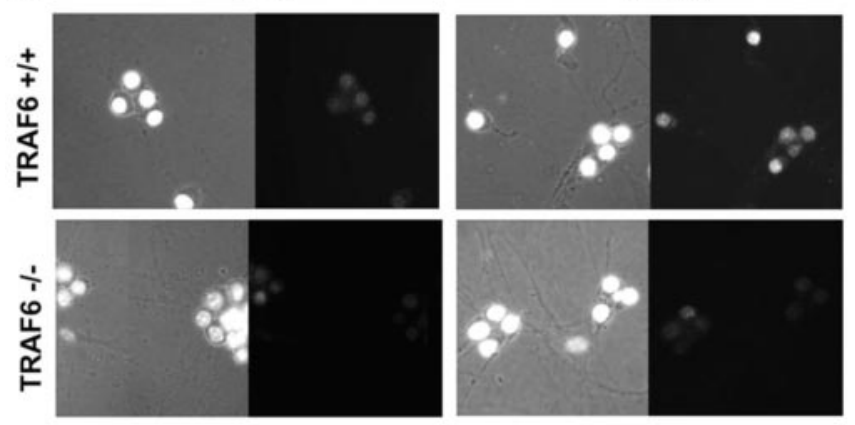

B.

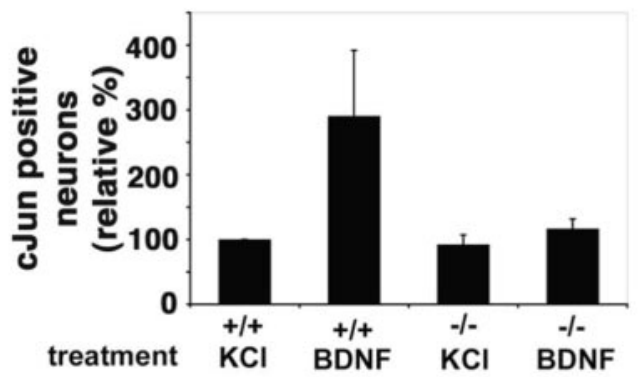

C.
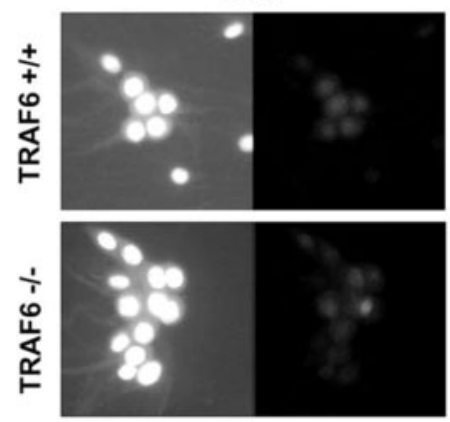

D.
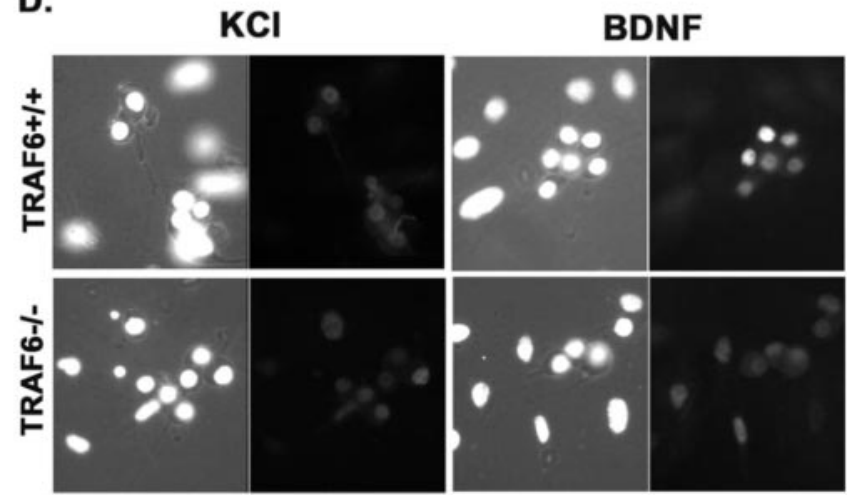

Figure 2. p75 stimulated nuclear accumulation of c-Jun, and phosphorylated c-Jun is deficient in traf6 $-/-$ sympathetic neurons. Sympathetic neurons were isolated from traf6 $+/+$ and traf6 - / - P3-P4 mouse pups and cultured with NGF ( $20 \mathrm{ng} / \mathrm{ml})$. After 3-5 $\mathrm{d}$ in culture, the NGF was removed, and the cells were refed media containing a neutralizing antibody to NGF and $12.5 \mathrm{~mm} \mathrm{KCl}$ with (BDNF) or without (KCl) the addition of $200 \mathrm{ng} / \mathrm{ml} \mathrm{BDNF}$. After $15-24 \mathrm{hr}$, the cells were fixed and immunostained using an antibody to c-Jun (Santa Cruz Biotechnology) or phospho-c-Jun (Cell Signaling Technology) and DAPI to identify healthy nuclei. Between 50 and 250 cells were counted for each experimental condition. A, Photomicrographs of the DAPIstained nuclei (left photomicrograph for each condition) and c-Jun immunofluorescence (right photomicrograph for each condition) for wild-type $(+/+)$ and traf6 null $(-/-)$ neurons. $B_{,}$ The graph depicts the effect of BDNF treatment on the number of neurons with nuclear $c-J u n$. The values are the means $\pm S D$, with the percentage of $c$-Jun-positive nuclei in the untreated (KCl) cultures set to $100 \%(n=4$ for $+/+$ and $n=3$ for $-/-$ ). C, To evaluate whether p75-independent JNK activation is intact in the absence of TRAF6, cultures were also treated
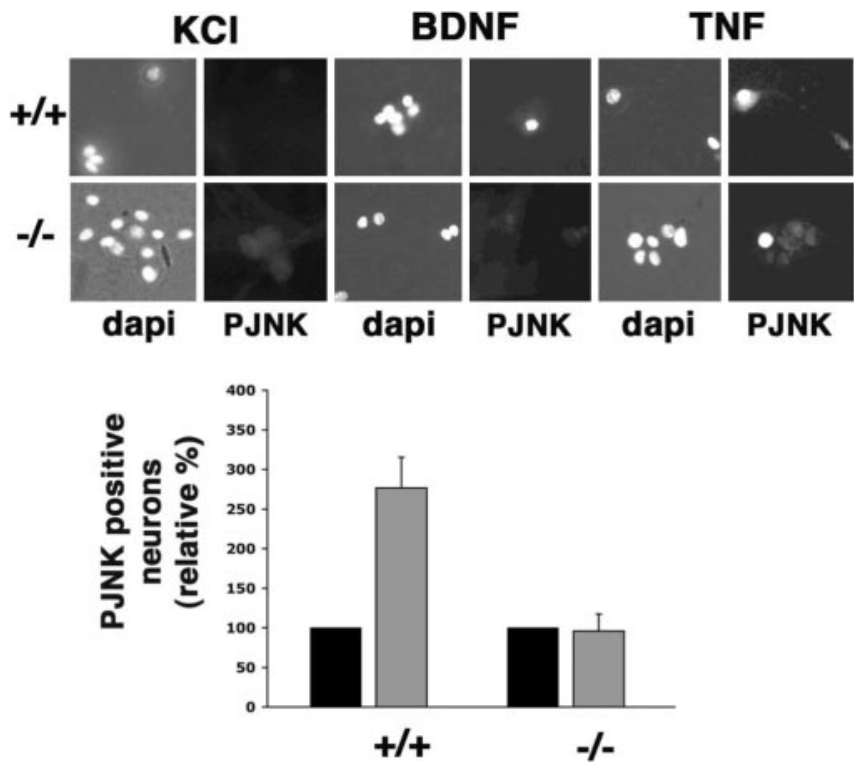

Figure 3. p75-mediated activation of JNK is deficient in traf6- $-/-$ sympathetic neurons. Sympathetic neurons were isolated from traf6 $+/+$ and traf6 $-/-\mathrm{P} 3-\mathrm{P} 4$ mouse pups and cultured with NGF $(20 \mathrm{ng} / \mathrm{ml})$. After $3-5 \mathrm{~d}$ in culture, the NGF was removed, and the cells were refed media containing a neutralizing antibody to NGF and $12.5 \mathrm{~mm} \mathrm{KCl}$ with or without the addition of $200 \mathrm{ng} / \mathrm{ml} \mathrm{BDNF}$ or $25 \mathrm{ng} / \mathrm{ml} \mathrm{TNF}$. After $8-24 \mathrm{hr}$, the cells were fixed and immunostained using an antibody to phospho-JNK (PJNK) and DAPI to identify healthy nuclei. Between 50 and 200 cells were counted for each experimental condition. Photomicrographs of the DAPIstained nuclei and PJNK immunofluorescence for wild-type $(+/+)$ and traf6 null $(-/-)$ neurons for each experimental condition (KCl only or BDNF) are shown. The graph depicts the effect of BDNF (gray bars) treatment on the number of neurons immunopositive for PJNK compared with no treatment ( $\mathrm{KCl}$ alone; black bars). The values are the means \pm SEM, with the percentage of PJNK-positive cells in the untreated cultures set to $100 \%$ ( $n=3$ for both genotypes).

the activation of JNK, we measured phospho-JNK by Western analysis. Schwann cells were cultured for 7-12 d, when RIP2 is downregulated and p75 activation is not likely to induce $\mathrm{NF} \kappa \mathrm{B}$ (Khursigara et al., 2001), and treated with $100 \mathrm{ng} / \mathrm{ml}$ NGF or vehicle for $5 \mathrm{hr}$ in serum-free media (to minimize basal activity). NGF induced phosphorylation of JNK in wild-type Schwann cells; however, there was no change in the phosphorylation status of JNK in cells from the traf6 null animals (Fig. $1 B$ ).

The lack of NF $\kappa \mathrm{B}$ and JNK activation in the null cells was specifically a result of deficient $\mathrm{p} 75$ signaling given that treatment with TNF $(25 \mathrm{ng} / \mathrm{ml})$, a receptor known to activate these pathways independent of p75 and TRAF6, caused an increase in JNK phosphorylation and $\mathrm{NF} \kappa \mathrm{B}$ activation in Schwann cells from wild-type and null cells (Fig. 1). Hence, these results confirm an essential role for TRAF6 in p75-mediated NF $\kappa \mathrm{B}$ activation and indicate that it is also necessary for the stimulation of the stress kinase, JNK.

with $25 \mathrm{ng} / \mathrm{ml}$ TNF. Photomicrographs show nuclei stained with DAPI (left) and immunostaining for (-Jun (right) in control (maintained in $20 \mathrm{ng} / \mathrm{ml} \mathrm{NGF)} \mathrm{cultures} \mathrm{from} \mathrm{both} \mathrm{traf6}+/+$ and traf6- $/$ - sympathetic neurons and in TNF-treated cultures. The increase in nuclear $c$-Jun shows that TNF stimulation will induce JNK activation in the presence or absence of TRAF6. D, Representative photomicrographs of immunostainings for phospho-c-Jun, the phosphorylated substrate of JNK, in wild-type and null cultures in the presence or absence of BDNF $(200 \mathrm{ng} / \mathrm{ml})$. Shown also in the left photomicrograph of each condition are the DAPI-stained nuclei $(n=2)$. 


\section{p75-dependent apoptosis in sympathetic neurons} requires TRAF6

One of the best characterized biological effects of $\mathrm{p} 75$ activation is apoptosis. This response has been particularly well documented in sympathetic neurons, both in vivo (Bamji et al., 1998; Majdan et al., 2001) and in vitro (Bamji et al., 1998; Palmada et al., 2002). Therefore, we chose to evaluate the effects of traf6 deletion in these neurons. The cell death program initiated by $\mathrm{p} 75$ has been suggested to require the activation of JNK, based on pharmacological inhibition of upstream kinases (Yoon et al., 1998) or by use of a dominant-negative JNK (Harrington et al., 2002). Because deletion of traf6 prevented p75 activation of JNK, we hypothesized that there would also be a corresponding attenuation in cell death.

Before evaluating the ability of BDNF to kill the neurons through p75, we first confirmed that the activation of JNK was deficient in these cells, as it was in Schwann cells. Sympathetic neurons express p75 and TrkA and depend on NGF for survival; therefore, to culture the neurons in the absence of neurotrophin, avoiding activation of both TrkA and p75, the cells were maintained in a mildly depolarizing media containing $12.5 \mathrm{~mm} \mathrm{KCl}$. Fifteen to $24 \mathrm{hr}$ after the addition of $100 \mathrm{ng} / \mathrm{ml}$ BDNF to wildtype neurons, the activation of this pathway was evaluated by immunostaining for c-Jun, which is upregulated after JNK activation and phospho-c-Jun, reflecting JNK phosphorylation (Fig. $2, A$ and $D$, respectively). It is important to note that although evaluating c-Jun is a convenient measure of JNK activity, this particular substrate of the kinase is not essential for p75mediated apoptosis in sympathetic neurons (Palmada et al., 2002). Compared with $\mathrm{KCl}$ alone, $\mathrm{BDNF}$ treatment resulted in an increase in nuclear c-Jun $(n=4)$ and phospho-c-Jun $(n=2 ; 8 \%$ in $\mathrm{KCl}$ and $47 \%$ in BDNF) in the wild-type neurons; however, in traf6-/- neurons, there was no change in the level of c-Jun $(n=$ 3 ) or phospho-c-Jun ( $n=2 ; 14 \%$ in $\mathrm{KCl}$ and $10 \%$ in BDNF), although TNF treatment, which is known to induce JNK and thus c-Jun, was able to induce an increase in nuclear c-Jun in both wild-type and null SCG neurons (Fig. 2C). In addition to measuring the activation of JNK by evaluating c-Jun, phospho-JNK immunostaining was performed. After BDNF and TNF treatment, an increase in JNK phosphorylation was observed in wildtype sympathetic neurons; however, in the null cells, TNF was able to induce JNK phosphorylation, but BDNF was not (Fig. 3). Hence, TRAF6 is required for p75-mediated JNK activation in sympathetic neurons, as well as Schwann cells.

Previous studies have shown that the JNK signal is required for p75-mediated cell death in oligodendrocytes (Yoon et al., 1998; Harrington et al., 2002); thus, we investigated the role of this kinase in sympathetic neurons after p75 activation. Before activation of p75 with BDNF, the neurons were infected with an adenovirus expressing a dominant-negative JNK2 (DN-JNK) that has been shown to block all JNK signaling (Harrington et al., 2002), or an adenovirus expressing GFP. To ensure that the DN-JNK adenovirus was blocking the JNK pathway, neurons were immunostained for c-Jun. Those neurons infected with DN-JNK exhibited no nuclear c-Jun, whereas those treated with the GFP virus upregulated c-Jun after BDNF treatment (data not shown).

After verifying that the JNK signal was abrogated by the virus, neurons were treated with $\mathrm{KCl}$ (Fig. 3, white bars) or BDNF (Fig. 3, black bars) for $48 \mathrm{hr}$, as described above, after infection by the GFP (control) or the DN-JNK-expressing adenovirus. BDNF treatment of GFP-infected, wild-type neurons lead to a $31 \%$ decrease in cell survival; however, no change in neuronal survival

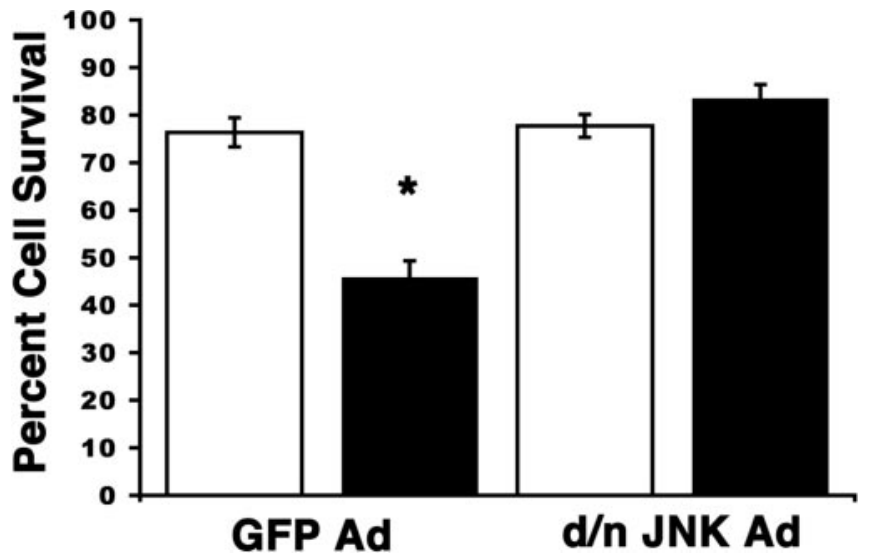

Figure 4. Inhibition of the JNK pathway blocks p75-mediated cell death in sympathetic neurons. P4 SCG neurons were isolated from wild-type pups and cultured in the presence of 20 $\mathrm{ng} / \mathrm{ml}$ NGF. Neurons were infected with either a GFP adenovirus or a dominant-negative JNK2 GFP-tagged adenovirus. Two days after the infection, NGF was removed from the media, and the cells were refed media containing a neutralizing antibody to NGF and $12.5 \mathrm{~mm} \mathrm{KCl}$ with (BDNF; black bars) or without (KCl; white bars) the addition of $200 \mathrm{ng} / \mathrm{ml} \mathrm{BDNF}$. Neurons were fixed and mounted with DAPI to evaluate nonapoptotic nuclei $48 \mathrm{hr}$ after the BDNF treatment. The percentages represent the number of viable neurons (with a nonapoptotic nucleus) of the total number of neurons for each treatment. Depicted are the mean and SEM from four separate experiments. Between 30 and 100 neurons were counted per condition. ${ }^{*} p \leq 0.01$; statistical significance using Student's $t$ test.

was observed after BDNF treatment of DN-JNK-expressing neurons (Fig. 4). Basal cellular apoptosis in the control conditions $(\mathrm{KCl})$ was not different between neurons infected with GFP $(22.5 \%)$ and DN-JNK (21.9\%). Given that cells infected with the DN-JNK adenovirus were resistant to p75-mediated cell death, these data indicate that JNK activation is required for p75 to induce cell death in sympathetic neurons after BDNF treatment.

To determine whether the loss of traf6 resulted in an attenuation of apoptosis induced by p75, the neurons from traf6 $6+/+$, traf6 $+/-$, and traf6-/- SCGs were treated with $100 \mathrm{ng} / \mathrm{ml}$ BDNF, and the number of surviving cells was determined after 48
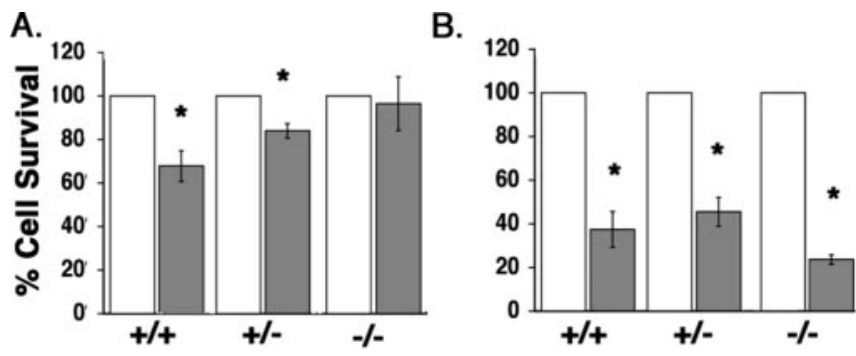

Figure 5. Loss of p75-mediated apoptosis in sympathetic neurons from traf6-/- mice. $A$, Sympathetic neuron survival after BDNF treatment. Sympathetic neurons from traf6 $+/+$, traf6 $+/-$, and traf6 - /- mice were cultured with NGF $(20 \mathrm{ng} / \mathrm{ml})$ for 3-4 d, rinsed, and refed with media containing a neutralizing antibody to NGF and $12.5 \mathrm{~mm} \mathrm{KCl}$ with (black bars) or without (white bars) the addition of $200 \mathrm{ng} / \mathrm{ml}$ BDNF. After $48 \mathrm{hr}$, the cells were fixed and stained with DAPI to identify neurons with nonapoptotic nuclei. The effect of BDNF is expressed relative to survival of control cultures for each genotype. Shown are the mean and SEM from five independent experiments. ${ }^{*} p<0.05$; statistical significance based on Student's $t$ test. B, Sympathetic neuron survival after NGF withdrawal. Sympathetic neurons were isolated from traf6 $+/+$, traf6 $+/-$, and traf6 $-/-$ mice and cultured 3-4 d with NGF $(20 \mathrm{ng} / \mathrm{ml})$. The neurons were then rinsed and refed with media containing a neutralizing antibody to NGF (black bars) or with media containing $20 \mathrm{ng} / \mathrm{mI} \mathrm{NGF} \mathrm{(white} \mathrm{bars).} \mathrm{After} 48 \mathrm{hr}$, the cells were fixed and stained with DAPI to evaluate nonapoptotic nuclei. Shown are the mean and SEM from five independent experiments. The effect of NGF withdrawal is expressed relative to cultures maintained in NGF for each genotype. ${ }^{*} p<0.05$; statistical significance based on Student's $t$ test. 
A.

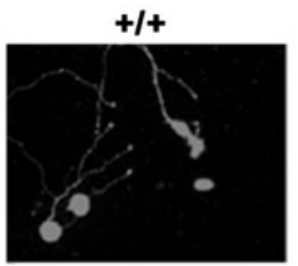

B.

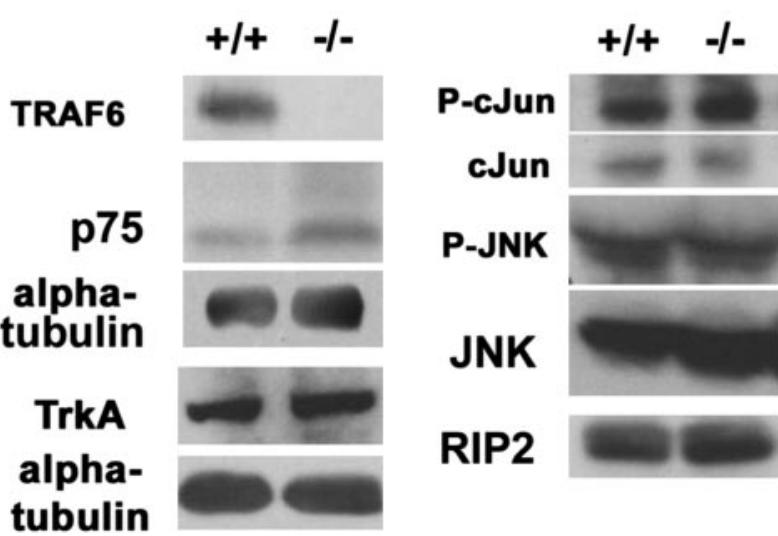

Figure 6. The expression of p75 and related signaling molecules are comparable in the absence and presence of TRAF6. $A$, Photomicrographs depict p75 immunostaining in sympathetic neurons from traf6 $+/+$ and traf6 $-/-$ mouse pups. $B$, Western blot analysis of total TRAF6, p75, TrkA, phospho-c-Jun, c-Jun, phospho-JNK, and JNK protein in whole-brain homogenates from traf6 $+/+$ and traf6 $-/-$ pups. The brains from two P3-P4 traf6 $+/+$ and traf6 $-/-$ mouse pups were isolated, homogenized, and $300 \mu \mathrm{g}$ of cleared total cell lysates were separated by SDS-PAGE and subjected to Western blot analysis. $\alpha$-Tubulin was used as a loading control.

hr. Neuronal survival was determined by counting the number of phase-bright neurons with nonapoptotic nuclear profiles, based on DAPI staining, and having neurites at least twice the length of the soma. BDNF activation of p75 significantly reduced neuronal survival in cultures isolated from traf $6+/+$ and traf $6+/-$ mice (to $68.0 \pm 7.0 \%$ and $84.0 \pm 3.3 \%$, respectively); however, there was no significant effect on neurons isolated from traf6 $-/-$ mice (Fig. 5A; white bars, $\mathrm{KCl}$; gray bars, BDNF). These results demonstrate that TRAF6 is required for p75-mediated cell death in sympathetic neurons.

The p75 cell death signal has been reported to differ from that induced after NGF withdrawal (Palmada et al., 2002). Therefore, we sought to determine whether the lack of TRAF6 affected apoptosis induced by removing NGF. In the presence of NGF, there was no difference observed in the basal survival level among the three genotypes (data not shown). Relative to cultures maintained in NGF (Fig. 5B, white bars), only $37.0 \pm 8.2 \%$ of traf $6+/+, 46.0 \pm 6.6 \%$ of traf $6+/-$, and $24.0 \pm 2.1 \%$ of traf6-/- neurons survived after $48 \mathrm{hr}$ of NGF withdrawal (Fig. $5 B$, gray bars), demonstrating that neurons from all traf6 genotypes are sensitive to removal of trophic factor and that this cell death occurs through a mechanism different from $\mathrm{p} 75$ activation (Fig. $5 B$ ). These results also indicate that the cell death induced by BDNF was specifically through p75 and not because of displacing residual NGF from a high-affinity p75-TrkA complex.

The lack of p75 signaling in the traf6-/- animals was not attributable to loss of expression of the receptor or other downstream targets of p75, because we found that the levels of expression were similar in both wild-type and null brain lysates (Fig. $6 B)$. In addition, all sympathetic neurons in the SCG cultures from wild-type and null cells were immunopositive for p75 (Fig. $6 A)$. This result is in accordance with previous findings that $\mathrm{p} 75$ - expressing neurons were still present in traf6-/- brain (Lomaga et al., 2000).

Developmental cell death is reduced in the SCGs of traf6- $/-$ mice

In $p 75-/-$ mice, the number of sympathetic neurons in the SCGs does not decrease during the normal period of developmental cell death (Bamji et al., 1998). This has been shown to be a result of reduced apoptosis (Majdan et al., 2001). Based on the loss of p75 signaling and the inability to transduce an apoptotic response in vitro that we observed in cells from traf6-/- mice, we predicted that these animals would also exhibit reduced naturally occurring cell death in sympathetic neurons in vivo, resulting in more neurons, similar to $p 75-/-$ animals. Therefore, we performed morphometric analysis of the SCGs from P8 traf $6+/+$ and traf6 $-/-$ littermates, a time point after the peak of apoptosis, but before the lethality attributable to deleting traf6. There was a marginal, but significant ( $p=0.05$; paired $t$ test), $12 \%$ increase in the neuronal number in the traf6- $-/-$ SCGs $(n=$ 3 for each genotype; data not shown). However, the interpretation of this analysis is complicated by the fact that these mice are markedly smaller, only $51 \%$ of the wild type by weight. Because it is well documented that the size of the target tissue is key for

A.
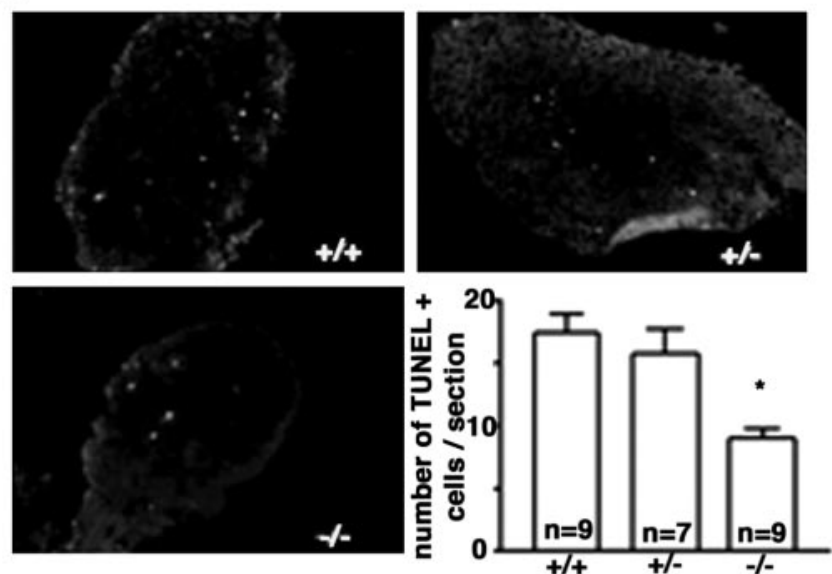

B.

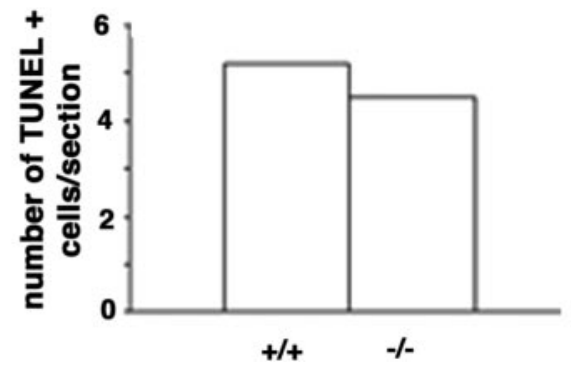

Figure 7. Developmental apoptosis is reduced in the early traf6-I- SCG. A, Visualization and quantitation of the number of TUNEL-positive cells per section from SCGs of traf6 $+/+$, traf6 $+/-$, and traf6 $-/-$ P4 mice. Whole SCGs were removed from pups on P4, frozen, serially sectioned, and TUNEL labeling was performed on every third section. At least four sections per animal were counted for TUNEL-positive cells. The number of TUNEL-positive cells per section for each animal was averaged. Photomicrographs are representative of nine traf6 $+/+$ and traf6 $+/-$ mice and seven traf6 $-/-$ mice. The graph depicts the average number of TUNEL-positive cells \pm SEM per section for each SCG. ${ }^{*} p<0.05$; statistical significance based on Student's $t$ test. $B$, SCGs were also taken from P12 mice and processed in the same manner as for the P4 pups. The number of dying cells in the older SCGs is not different between the two genotypes. The graph depicts the number of TUNEL-positive cells per section per ganglia for two traf6 $+/+$ and four traf6 $-/-$ mice. 
determining the neuronal number, this would suggest that the absolute counts substantially underestimate the effects of deleting traf6 on naturally occurring cell death in the ganglia. Indeed, if we correct for the total weight of the animal, then the difference is $125 \%$ more neurons per ganglia in the null mice compared with wild-type mice. This is very similar to the differences observed in the p75-/- mice compared with wild-type animals at P23, in which there were $130 \%$ more neurons per ganglia in $p 75-/-$ mice.

To more directly compare the level of cell death, we evaluated the number of apoptotic cells in the SCGs from P4 mice, a time when sympathetic neurons undergo p75-dependent cell death (Bamji et al., 1998), and P12, after the peak of apoptosis and the latest possible time point in these animals. Using the TUNEL assay to quantitate apoptosis in serially sectioned SCGs from traf6 wild-type, heterozygous, and null animals, we found significantly fewer dying cells in the ganglia of traf6-/- mice on P4 (Fig. 7A) but not on P12 (Fig. 7B). Thus, like in the p75-/-SCGs, in the absence of TRAF6 there is a disruption in the normal developmental apoptosis of sympathetic neurons.

\section{Discussion}

A number of intracellular binding proteins that associate with the p75 neurotrophin receptor have been identified (Roux and Barker, 2002); however, it remains to be determined how these contribute to the signals generated by this receptor. Here, we demonstrate that a member of the TRAF family, TRAF6, is essential for activation of $\mathrm{NF} \kappa \mathrm{B}$ and JNK by neurotrophin binding to p75. In addition, we found that cells from these animals were deficient in p75-dependent cell death and sympathetic neurons did not die after BDNF treatment. In contrast, neuronal cell death induced by NGF withdrawal, a mechanism of cell death known to be independent of p75 signal transduction, was not affected by the absence of TRAF6. Finally, in vivo, there was a reduction in the level of naturally occurring cell death in the SCGs of traf6-/animals relative to the wild type. This is similar to what was reported for $p 75-/-$ mice (Majdan et al., 2001). Taken together, these results suggest that the normal apoptosis that occurs during development in the SCGs requires signaling through a p75TRAF6 pathway.

TRAF6 is a member of a family of six TRAFs, first identified by their ability to bind to members of the TNF receptor family (Inoue et al., 2000; Bradley and Pober, 2001). All of the TRAFs share a region of homology in their $\mathrm{C}$ terminus, including a coiled-coil domain and a sequence referred to as the TRAF-C domain, which mediates the association with receptors as well as binding to other TRAFs. In addition, all members of the family, except TRAF1, have a series of zinc fingers and a ring-finger domain at their $\mathrm{N}$-terminal region that are essential for downstream signaling. TRAFs 2, 5, and 6 have been shown to activate NF $\kappa$ B and JNK after overexpression or in response to the activation of a number of receptors in the TNF receptor superfamily (Inoue et al., 2000; Bradley and Pober, 2001). Among the TRAFs, TRAF6 is the most divergent member, and its mechanism of activating $\mathrm{NF} \kappa \mathrm{B}$ has been shown to depend on its ability to act as an E3 ubiquitin ligase (Deng et al., 2000). In response to receptor-induced oligomerization, TRAF6 attaches to itself a unique poly-ubiquitin chain, polymerized through lysine 63 as opposed to the more customary lysine 48 . This modification activates the downstream kinase transforming growth factor $\beta$-activated kinase (TAK), resulting in activation of $\mathrm{I} \kappa \mathrm{B}$ (inhibitor of nuclear factor $-\kappa \mathrm{B}$ ) kinase and, subsequently, $\mathrm{NF} \kappa \mathrm{B}$. TAK activation is also required for the stimulation of JNK and the kinase p38 (Wang et al., 2001).

Previous analysis of traf6 $-/-$ mice confirmed an essential role for this protein in mediating signals from CD40, RANK, TLR, and IL-1 receptor (Ishida et al., 1996; Lomaga et al., 1999; Naito et al., 1999; Armstrong et al., 2002); however, the effect on p75 signaling was not investigated. The traf6 $-/-$ mice do have a neural phenotype (in 35\% of the animals there is a failure of neural tube closure) (Lomaga et al., 2000), but this is not likely to be mediated by $\mathrm{p} 75$ because no such phenotype has been reported in the $p 75-/-$ mice (Lee et al., 1992; von Schack et al., 2001). Lomaga et al. (2000) reported that the number of p75-expressing cells in the traf6-/- brain did not appear to be dramatically affected; however, they did not perform a quantitative analysis nor were known p75-regulated processes investigated.

An involvement of TRAF6 in signaling through the p75 neurotrophin receptor was first proposed based on the association of the two proteins and the ability of a dominant-negative TRAF6 to prevent activation of $\mathrm{NF} \kappa \mathrm{B}$ in Schwann cells by NGF (Khursigara et al., 1999; Foehr et al., 2000). However, it was recently reported that TRAF6 was not able to reconstitute NGF-p75-stimulated $\mathrm{NF} \kappa \mathrm{B}$ in HEK293 cells. Moreover, RIP2, another adaptor protein that associates with members of the TNF receptor family, was sufficient and necessary for p75 to activate the transcription factor (Khursigara et al., 2001). These authors suggested that TRAF6 is involved in the stimulation of JNK by p75, whereas RIP2 mediates signaling to $\mathrm{NF} \kappa \mathrm{B}$. Our results from analyzing the knockout animals demonstrate that TRAF6 is required for p75 to activate both the $\mathrm{NF} \kappa \mathrm{B}$ and JNK pathways. These seemingly contradictory findings likely reflect the involvement of both TRAF6 and RIP2 in p75 signaling. Indeed, it has been shown that RIP2-mediated NF $\kappa$ B activation can be inhibited by dominantnegative TRAF6 and TRAF6, as well as other TRAFs, can bind to RIP2 and recruit it to receptor complexes (McCarthy et al., 1998). The expression of TRAF6 and p75 may not be sufficient to activate NF $\kappa \mathrm{B}$ without adaptor proteins like RIP2, whereas overexpression of RIP2 may recruit other TRAFs, endogenously expressed in 293 cells, in place of TRAF6 to p75 and facilitate NF $\kappa \mathrm{B}$ activation. It is noteworthy that p75 was shown to bind directly to RIP2 (Khursigara et al., 2001), whereas TRAF6 was only coimmunoprecipitated (Khursigara et al., 1999; Foehr et al., 2000). Structure analysis of several TRAF6-binding proteins has defined a general consensus binding sequence, Pro-X-Glu-X-X-aromatic or acidic residue (Ye et al., 2002), and no such sequence is present in the cytoplasmic tail of p75. Moreover, Mamidipudi et al. (2002) reported that IRAK, an adaptor protein involved in recruiting TRAF6 to the IL-1 receptor, was required for TRAF6 binding to p75. Hence, TRAF6 may be recruited to the receptor where it serves as an integral part of a larger signaling complex. Consistent with the existence of such a multi-component signaling complex, TRAF6 was recently shown to associate with another p75 ICD binding protein, NRIF, which is required for the receptor to induce apoptosis (Gentry et al., 2004).

The activation of JNK by $\mathrm{p} 75$ has been implicated as mediating the apoptotic signal based on pharmacological inhibition of the JNK pathway (Yoon et al., 1998) and using a dominantnegative JNK (Harrington et al., 2002) in oligodendrocytes. Similarly, here we demonstrate that p75 activation of JNK is required for the apoptotic signal in sympathetic neurons. In addition, we found that loss of TRAF6 resulted in a loss of JNK signaling and an abrogation of p75-mediated apoptosis. The activation of JNK by 75 was reported to involve the GTP-binding protein Rac1, based on the ability of a dominant-negative Racl to inhibit the stimulation of JNK by neurotrophin binding to p75 (Harrington et al., 2002). It is unclear whether TRAF6 and Racl are sequential in a pathway or are codependent and acting as essential parts of a 
signaling complex. Interestingly, the activation of $\mathrm{NF} \kappa \mathrm{B}$ by IL-1 was recently reported to involve both TRAF6 and Rac1, because both of these proteins were found to be part of a receptor complex, and dominant negatives of either blocked the downstream affects of the other (Jefferies et al., 2001). Hence, as was discussed previously, TRAF6 is likely an essential part of a multi-protein receptor complex.

To investigate the physiological role of TRAF6 in p75 signaling, we chose to focus on cell death induced by the receptor in sympathetic neurons. Miller and colleagues have demonstrated that selective activation of p75 in cultured rat sympathetic neurons stimulates apoptosis (Bamji et al., 1998). These authors also demonstrated a reduction in the amount of naturally occurring cell death in the SCGs from p75-/- mice. Similarly, we found that traf6-/ - neurons were resistant to 775 -mediated apoptosis and that developmental cell death was reduced in the traf6-/SCGs. Interestingly, if the traf6-/- neurons were maintained in NGF, withdrawal of trophic support resulted in apoptosis. These results indicate that the normal neuronal loss in vivo is not simply a result of the limited availability of NGF, as the classic neurotrophin hypothesis would suggest. Rather, there may also be an active role for $\mathrm{p} 75$ in eliminating these neurons. BDNF is produced by the SCG in vivo (Causing et al., 1997), thus there may be a constitutive apoptotic signal through p 75 that is only inactivated by NGF stimulation of TrkA. In accordance with this notion, Majdan et al. (2001) recently analyzed the neurons in the SCG of p75-/-, TrkA-I- double knock-out mice and found that although $\operatorname{Trk} A-/-$ mice exhibit a dramatic loss in these neurons, codeletion of $p 75$ substantially rescued the number of neurons in the SCGs.

In summary, our results demonstrate that TRAF6 is an essential mediator of p 75 signaling to both $\mathrm{NF} \kappa \mathrm{B}$ and JNK, most likely as part of a complex of proteins, or a receptor signalosome. How these two signaling paths are regulated to result in cell death or survival remains to be determined, but likely will be determined by the specific make up of the p75 signalosome in various cellular contexts. Nevertheless, our findings demonstrate that TRAF6 is required for the receptor to induce programmed cell death and thereby regulate the proper development of the mammalian nervous system.

\section{References}

Armstrong AP, Tometsko ME, Glaccum M, Sutherland CL, Cosman D, Dougall WC (2002) A RANK/TRAF6-dependent signal transduction pathway is essential for osteoclast cytoskeletal organization and resorptive function. J Biol Chem 277:44347-44356.

Bamji SX, Majdan M, Pozniak CD, Belliveau DJ, Aloyz R, Kohn J, Causing CG, Miller FD (1998) The p75 neurotrophin receptor mediates neuronal apoptosis and is essential for naturally occurring sympathetic neuron death. J Cell Biol 140:911-923.

Barbacid M (1994) The Trk family of neurotrophin receptors. J Neurobiol 25:1386-1403.

Bhakar AL, Roux PP, Lachance C, Kryl D, Zeindler C, Barker PA (1999) The p75 neurotrophin receptor (p75NTR) alters tumor necrosis factormediated NF-kappaB activity under physiological conditions, but direct p75NTR-mediated NF-kappaB activation requires cell stress. J Biol Chem 274:21443-21449.

Bradley JR, Pober JS (2001) Tumor necrosis factor receptor-associated factors (TRAFs). Oncogene 20:6482-6491.

Bui NT, Konig HG, Culmsee C, Bauerbach E, Poppe M, Krieglstein J, Prehn $\mathrm{JH}$ (2002) p75 neurotrophin receptor is required for constitutive and NGF-induced survival signalling in PC12 cells and rat hippocampal neurones. J Neurochem 81:594-605.

Cao Z, Xiong J, Takeuchi M, Kurama T, Goeddel DV (1996) TRAF6 is a signal transducer for interleukin-1. Nature 383:443-446.

Casaccia-Bonnefil P, Carter BD, Dobrowsky RT, Chao MV (1996) Death of oligodendrocytes mediated by the interaction of nerve growth factor with its receptor p75. Nature 383:716-719.

Causing CG, Gloster A, Aloyz R, Bamji SX, Chang E, Fawcett J, Kuchel G, Miller FD (1997) Synaptic innervation density is regulated by neuronderived BDNF. Neuron 18:257-267.

Davey F, Davies AM (1998) TrkB signalling inhibits p75-mediated apoptosis induced by nerve growth factor in embryonic proprioceptive neurons. Curr Biol 8:915-918.

DeFreitas MF, McQuillen PS, Shatz CJ (2001) A novel p75NTR signaling pathway promotes survival, not death, of immunopurified neocortical subplate neurons. J Neurosci 21:5121-5129.

Deng L, Wang C, Spencer E, Yang L, Braun A, You J, Slaughter C, Pickart C, Chen ZJ (2000) Activation of the IkappaB kinase complex by TRAF6 requires a dimeric ubiquitin-conjugating enzyme complex and a unique polyubiquitin chain. Cell 103:351-361.

Foehr ED, Lin X, O'Mahony A, Geleziunas R, Bradshaw RA, Greene WC (2000) NF- $\kappa$ B signaling promotes both cell survival and neurite process formation in nerve growth factor-stimulated PC12 cells. J Neurosci 20:7556-7563.

Frade JM, Barde YA (1998) Microglia-derived nerve growth factor causes cell death in the developing retina. Neuron 20:35-41.

Frade JM, Barde YA (1999) Genetic evidence for cell death mediated by nerve growth factor and the neurotrophin receptor p75 in the developing mouse retina and spinal cord. Development 126:683-690.

Frade JM, Rodriguez-Tebar A, Barde YA (1996) Induction of cell death by endogenous nerve growth factor through its p75 receptor. Nature 383:166-168.

Gentry JJ, Casaccia-Bonnefil P, Carter BD (2000) Nerve growth factor activation of nuclear factor kappaB through its $\mathrm{p} 75$ receptor is an antiapoptotic signal in RN22 schwannoma cells. J Biol Chem 275:7558-7565.

Gentry JJ, Rutkoski NJ, Burke TL, Carter BD (2004) A functional interaction between the p75 neurotrophin receptor interacting factors, TRAF6 and NRIF. J Biol Chem 279:16646-16656.

Hamanoue M, Middleton G, Wyatt S, Jaffray E, Hay RT, Davies AM (1999) p75-mediated NF-kappaB activation enhances the survival response of developing sensory neurons to nerve growth factor. Mol Cell Neurosci 14:28-40.

Harrington AW, Kim JY, Yoon SO (2002) Activation of Rac GTPase by p75 is necessary for c-jun $\mathrm{N}$-terminal kinase-mediated apoptosis. J Neurosci 22:156-166.

Huang EJ, Reichardt LF (2001) Neurotrophins: roles in neuronal development and function. Annu Rev Neurosci 24:677-736.

Inoue J, Ishida T, Tsukamoto N, Kobayashi N, Naito A, Azuma S, Yamamoto $\mathrm{T}$ (2000) Tumor necrosis factor receptor-associated factor (TRAF) family: adapter proteins that mediate cytokine signaling. Exp Cell Res 254:14-24

Ishida T, Mizushima S, Azuma S, Kobayashi N, Tojo T, Suzuki K, Aizawa S, Watanabe T, Mosialos G, Kieff E, Yamamoto T, Inoue J (1996) Identification of TRAF6, a novel tumor necrosis factor receptor-associated factor protein that mediates signaling from an amino-terminal domain of the CD40 cytoplasmic region. J Biol Chem 271:28745-28748.

Jefferies C, Bowie A, Brady G, Cooke EL, Li X, O’Neill LA (2001) Transactivation by the $\mathrm{p} 65$ subunit of NF-kappaB in response to interleukin-1 (IL-1) involves MyD88, IL-1 receptor-associated kinase 1, TRAF-6, and Rac1. Mol Cell Biol 21:4544-4552.

Khursigara G, Orlinick JR, Chao MV (1999) Association of the p75 neurotrophin receptor with TRAF6. J Biol Chem 274:2597-2600.

Khursigara G, Bertin J, Yano H, Moffett H, DiStefano PS, Chao MV (2001) A prosurvival function for the p75 receptor death domain mediated via the caspase recruitment domain receptor-interacting protein 2. J Neurosci 21:5854-5863.

Kobayashi N, Kadono Y, Naito A, Matsumoto K, Yamamoto T, Tanaka S, Inoue J (2001) Segregation of TRAF6-mediated signaling pathways clarifies its role in osteoclastogenesis. EMBO J 20:1271-1280.

Lee KF, Li E, Huber LJ, Landis SC, Sharpe AH, Chao MV, Jaenisch R (1992) Targeted mutation of the gene encoding the low affinity NGF receptor p75 leads to deficits in the peripheral sensory nervous system. Cell 69:737-749.

Lomaga MA, Yeh WC, Sarosi I, Duncan GS, Furlonger C, Ho A, Morony S, Capparelli C, Van G, Kaufman S, van der Heiden A, Itie A, Wakeham A, Khoo W, Sasaki T, Cao Z, Penninger JM, Paige CJ, Lacey DL, Dunstan CR, 
et al. (1999) TRAF6 deficiency results in osteopetrosis and defective interleukin-1, CD40, and LPS signaling. Genes Dev 13:1015-1024.

Lomaga MA, Henderson JT, Elia AJ, Robertson J, Noyce RS, Yeh WC, Mak TW (2000) Tumor necrosis factor receptor-associated factor 6 (TRAF6) deficiency results in exencephaly and is required for apoptosis within the developing CNS. J Neurosci 20:7384-7393.

Longo FM, Manthorpe M, Xie YM, Varon S (1997) Synthetic NGF peptide derivatives prevent neuronal death via a 75 receptor-dependent mechanism. J Neurosci Res 48:1-17.

Majdan M, Walsh GS, Aloyz R, Miller FD (2001) TrkA mediates developmental sympathetic neuron survival in vivo by silencing an ongoing p75NTR-mediated death signal. J Cell Biol 155:1275-1285.

Mamidipudi V, Li X, Wooten MW (2002) Identification of interleukin 1 receptor-associated kinase as a conserved component in the p75neurotrophin receptor activation of nuclear factor-kappa B. J Biol Chem 277:28010-28018.

McCarthy JV, Ni J, Dixit VM (1998) RIP2 is a novel NF-kappaB-activating and cell death-inducing kinase. J Biol Chem 273:16968-16975.

McQuillen PS, DeFreitas MF, Zada G, Shatz CJ (2002) A novel role for p75NTR in subplate growth cone complexity and visual thalamocortical innervation. J Neurosci 22:3580-3593.

Naito A, Azuma S, Tanaka S, Miyazaki T, Takaki S, Takatsu K, Nakao K, Nakamura K, Katsuki M, Yamamoto T, Inoue J (1999) Severe osteopetrosis, defective interleukin-1 signalling and lymph node organogenesis in TRAF6-deficient mice. Genes Cells 4:353-362.

Palmada M, Kanwal S, Rutkoski NJ, Gufstafson-Brown C, Johnson RS, Wisdom R, Carter BD (2002) c-jun is essential for sympathetic neuronal death induced by NGF withdrawal but not by p75 activation. J Cell Biol 158:453-461.

Roux PP, Barker PA (2002) Neurotrophin signaling through the p75 neurotrophin receptor. Prog Neurobiol 67:203-233.

von Schack D, Casademunt E, Schweigreiter R, Meyer M, Bibel M, Dechant G (2001) Complete ablation of the neurotrophin receptor p75NTR causes defects both in the nervous and the vascular system. Nat Neurosci 4:977-978.

Wang C, Deng L, Hong M, Akkaraju GR, Inoue J, Chen ZJ (2001) TAK1 is a ubiquitin-dependent kinase of MKK and IKK. Nature 412:346-351.

Wang KC, Kim JA, Sivasankaran R, Segal R, He Z (2002) p75 interacts with the Nogo receptor as a co-receptor for Nogo, MAG and OMgp. Nature 420:74-78.

Weibel ER (1989) Measuring through the microscope: development and evolution of stereological methods. J Microsc 155:393-403.

Wong ST, Henley JR, Kanning KC, Huang KH, Bothwell M, Poo MM (2002) A p75(NTR) and Nogo receptor complex mediates repulsive signaling by myelin-associated glycoprotein. Nat Neurosci 5:1302-1308.

Ye H, Arron JR, Lamothe B, Cirilli M, Kobayashi T, Shevde NK, Segal D, Dzivenu OK, Vologodskaia M, Yim M, Du K, Singh S, Pike JW, Darnay BG, Choi Y, Wu H (2002) Distinct molecular mechanism for initiating TRAF6 signalling. Nature 418:443-447.

Yoon SO, Casaccia-Bonnefil P, Carter B, Chao MV (1998) Competitive signaling between TrkA and p75 nerve growth factor receptors determines cell survival. J Neurosci 18:3273-3281.

Yoshida H, Naito A, Inoue J, Satoh M, Santee-Cooper SM, Ware CF, Togawa A, Nishikawa S (2002) Different cytokines induce surface lymphotoxinalphabeta on IL-7 receptor-alpha cells that differentially engender lymph nodes and Peyer's patches. Immunity 17:823-833. 